\title{
Heat transfer enhancement in solar air heater
}

\author{
A.M. Lanjewar, J.L. Bhagoria and R.M. Sarviya \\ Dept. of Mechanical Engineering, M.A.N.I.T., Bhopal-462051, Madhya Pradesh, India.
}

lanjewar_atul@yahoo.com

\begin{abstract}
This paper presents results of an experimental investigation of heat transfer in rectangular duct with repeated ribs in Wcontinuous pattern. The ribs in W-pattern have been tested for both pointing upstream (W-up) and downstream (Wdown) to the flow. The duct has width to height ratio of 8 , relative roughness pitch of 10 , relative roughness height of 0.03375 , angle of attack of ribs in W-pattern is $45^{\circ}$ and Reynolds number ranges from 2300-14000. Roughened wall of the duct is uniformly heated while the remaining three walls are insulated. These conditions correspond closely to those found in solar air heaters. The heat transfer results have been compared with those for smooth ducts under similar flow and thermal boundary condition. Enhancement of heat transfer by providing W-shape roughness is 2.39 times to that of smooth plate for W-down ribs and 2.21 times to that of smooth plate for W-up ribs respectively.
\end{abstract}

Keywords: Solar air heater, heat transfer and W-shape rib roughness.

\section{Introduction}

Solar air heaters have low efficiency due to low convective heat transfer coefficient between the air and absorber plate that leads to higher temperature of the absorber plate leading to maximum thermal losses to environment (Prasad et al., 1983). Artificial roughness on the airflow side of the absorber plate has been employed in various ways to improve the thermal efficiency of solar air heaters (Prasad et al., 1988; Karwa et al., 1999; Muluwork et al., 2000; Bhagoria et al., 2002; Momin et al., 2002; Karwa et al., 2003). Studies carried out for gas turbine cooling channels (Han et al., 1978; Lau et al., 1991; Han et al., 1992; Taslim et al., 1996) have shown that ribs oriented at $45^{\circ}$ to $60^{\circ}$ inclination to the flow perform better than transverse ribs. The present investigation is taken up with the objective of experimentation on $45^{\circ} \mathrm{W}$-shaped ribs as artificial roughness glued by epoxy resin to the underside of one broad wall of the duct to collect data on heat transfer and fluid flow characteristics. The data will be presented in the form of Stanton number plot to bring out clearly the effect of parameters and enhancement in heat transfer achieved as a result of providing artificial roughness. The ribs have been tested both pointing upstream (W-up) and downstream (W-down) to the flow.

\section{Details of experimental set-up}

The experimental set up is an indoor open flow loop that consists of a test duct with entrance and exit sections, a blower, control valve, orifice plate and various devices for measurement of temperature and fluid head. The test section is of length $1500 \mathrm{~mm}\left(33.75 \mathrm{D}_{\mathrm{h}}\right)$. The entry and exit lengths are $177 \mathrm{~mm}$
$(2.5 \sqrt{ } \mathrm{WH})$ and $354 \mathrm{~mm}(5 \sqrt{\mathrm{WH}})$ respectively (ASHRAE, 1977). The test section carries the roughened absorber plate at the top. The exit section of $354 \mathrm{~mm}$ length is used after the test section in order to reduce the end effect in the test section. In the exit section after $130 \mathrm{~mm}$ three equally spaced baffles are provided in $87 \mathrm{~mm}$ length for the purpose of mixing the hot air coming out of solar air duct to obtain a uniform temperature of air at the outlet. The outside of the entire set-up, from the inlet to the orifice plate is insulated with $25 \mathrm{~mm}$ thick thermocol. The heated plate is $1 \mathrm{~mm}$ thick G.I. sheet having W-shaped ribs glued on its rear side by epoxy resin and this forms the top broad wall of the duct. The mass flow rate of air is measured by means of a orifice meter connected with an inclined manometer and the flow is controlled by the control valves provided in the lines. Calibrated copperconstantan thermocouples were used to measure the air and the heated plate temperatures at different locations. A digital micro-voltmeter is used to indicate the output of the thermocouples. The optimum value of p/e is reported to be 10 (Han et al., 1978; Momin et al., 2002). For the rectangular ducts researchers (Lau et al., 1991; Han et al., 1992; Momin et al., 2002) have reported an optimum rib angle of $45^{\circ}$ to $60^{\circ}$. The schematic of the experimental set up is shown in Fig. 1, Fig. 2a and b show details of roughened plate.

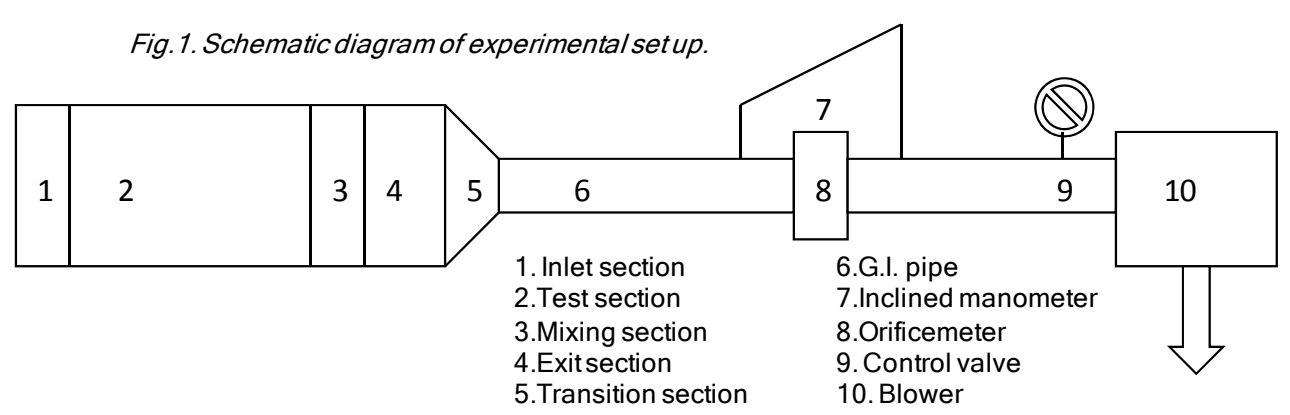

5.Transition section 
Indian Journal of Science and Technology

Fig. 2a. W-down rib orientation.

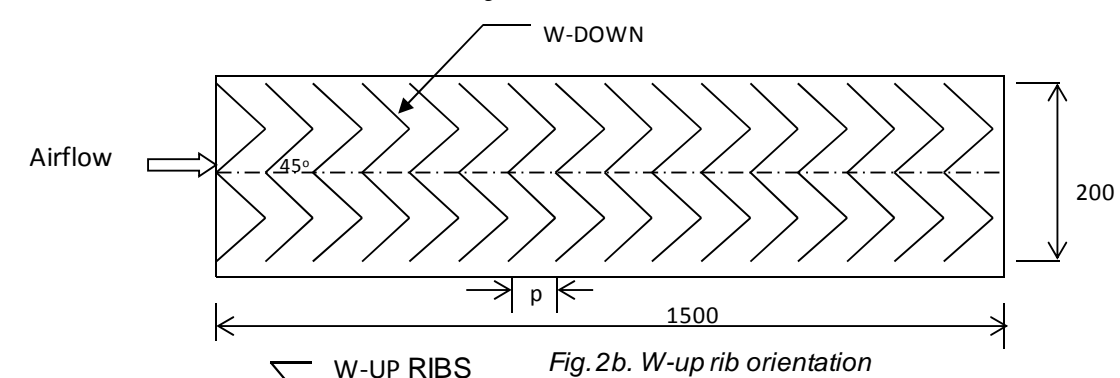

W-UP RIBS Fig. 2b. W-up rib orientation
Vol. 3 No. 8 (Aug 2010)

ISSN: 0974- 6846

\section{Results}

Validity test: Friction factor and Nusselt number determined from the experimental data on a smooth duct were compared with those obtained from the modified Blasius eqn. (1) for friction factor and modified Dittus - Boelter (Sadik et al., 1987) eqn. (2) for Nusselt number.

\section{Modified Blasius equation}

$$
f_{\mathrm{s}}=0.085 \operatorname{Re}^{-0.25}
$$

Modified Dittus-Boelter equation

$$
N u_{s}=0.023 \times \operatorname{Re}^{0.8} \times \operatorname{Pr}^{0.4} \times\left(2 R_{a v} / D_{e}\right)^{-0.2}
$$

\section{Experimental procedure}

Before starting all components of setup, the instruments have been checked for proper operation. The blower is then switched on and joints have been checked for leakage. Flow control valve is adjusted to give a predetermined rate of airflow to the test section after switching on the blower. Under steady state conditions the test runs to collect relevant heat transfer data were conducted. For each rib configuration 7 runs have been conducted at air-flow rates corresponding to the flow Reynolds numbers between 2300 and 14000 . After each change of flow rate, the system was allowed to attain steady state before the data were recorded. Table 1 gives range of parameters for investigation. The following parameters were measured during the experiments: 1 . Pressure drop across the orifice plate, 2. Inlet air temperature of collectors, 3 . Outlet air temperature of collectors, 4 . Temperature of plate.

Fig. 3. Comparision of experimental \& predicted values of Nusselt number for smooth duct

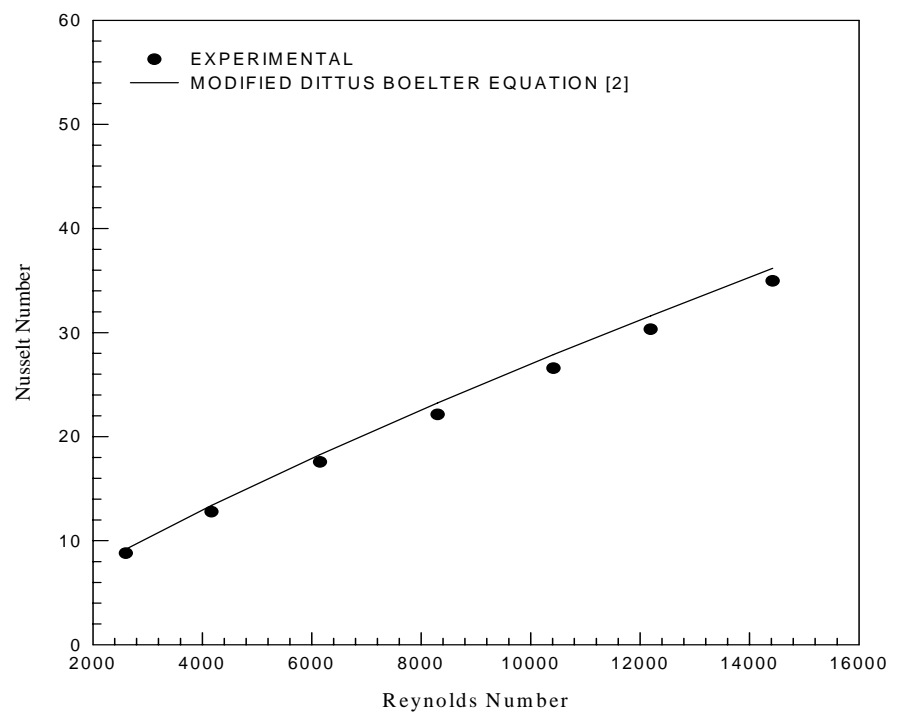

where $2 R_{a v} / D_{e}=(1.156+H / W-1) /(H / W)$

for rectangular channel

where $f_{s}$ is friction factor for smooth duct, $R e$ is Reynolds number, $\mathrm{Nu}_{\mathrm{s}}$ is Nusselt number for smooth duct, $\mathrm{P}_{\mathrm{r}}$ is Prandtl number, $\mathrm{H}$ is duct height $(\mathrm{m})$ and $\mathrm{W}$ is duct width (m). Comparison of experimental and predicted values of Nusselt number and friction factor is shown in Fig. 3 and Fig. 4 respectively. It is seen that the smooth plate data for Friction factor and Nusselt number agree reasonably well with the values predicted by eqn. (1) and eqn. (2) respectively. As the experimental values for both the friction factor and Nusselt number are in reasonably good agreement with predicted values the validity of the experimental results is ensured.

The variation of Stanton number with Reynolds number for W-down and W-up ribs is shown in Fig. 5. It reveals that $\mathrm{W}$ - down ribs have higher Stanton number ratio than W-up ribs for the entire range of Reynolds number studied indicating clearly the effect of orientation of ribs. Thus, $45^{\circ} \mathrm{W}$-down ribs have better performance than $45^{\circ}$ up ribs in the range of parameters investigated. The results are in broad agreement with previous investigations on V-shaped ribs (Karwa, 2003).

\section{Conclusion}

On the basis of this investigation on heat transfer characteristics in solar air duct having ribs on absorber plate, following conclusions have been drawn: Roughened solar air heaters perform better as compared to smooth heaters. Solar air heater having W-shaped ribs pointing downstream have better performance than $\mathrm{W}$ shaped ribs pointing upstream to the flow. The maximum enhancement in Stanton number is 2.39 for W-down and 2.21 for W-up ribs respectively over smooth plate.
Research article

CIndian Society for Education and Environment (iSee)
"Solar heater" http://www.indjst.org
Lanjewar et al. Indian J.Sci.Technol. 
Table 1. Range of parameters for investigation

\begin{tabular}{|l|l|}
\hline Parameter & Values \\
\hline Reynolds number & $2300-14000$ \\
\hline Relative roughness height $\left(e / D_{h}\right)$ & 0.03375 \\
\hline Relative roughness pitch $(p / e)$ & 10 \\
\hline Rib angle of attack $(\alpha)$ & $45^{\circ}$ \\
\hline Thickness of plate & $1 \mathrm{~mm}$ \\
\hline Channel aspect ratio $(W / H)$ & 8 \\
\hline Test length & $1500 \mathrm{~mm}$ \\
\hline Hydraulic diameter & $44.44 \mathrm{~mm}$ \\
\hline
\end{tabular}

Fig. 4. Comparision of experimental \& predicted values of friction factor for smooth duct

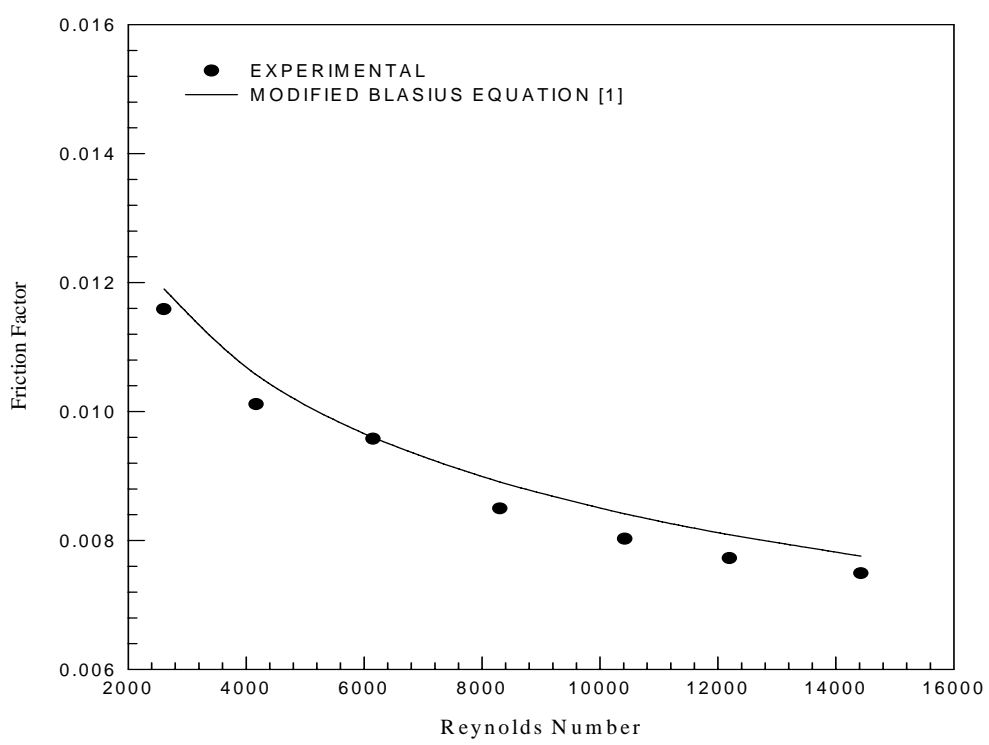

Fig. 5. Stanton number ratio versus Reynolds number for $W$-down \& $W$-up ribs

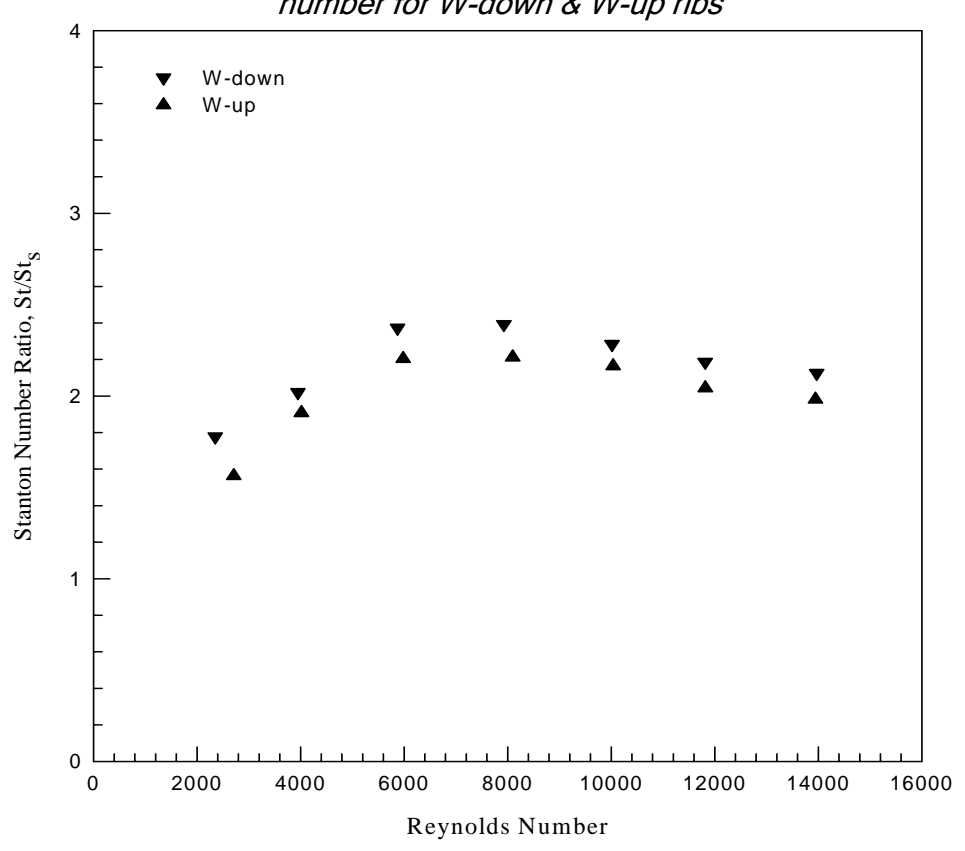

\section{References}

1. ASHRAE Standard 93-77 (1977) Method of testing to determine the thermal performance of solar air heater. American Society for Heating, Refrigeration, and AirConditioning Engineering, NY. pp: 1-34.

2. Bhagoria JL, Saini JS and Solanki SC (2002) Heat transfer coefficient and friction factor correlations for rectangular solar air heater duct having transverse wedge shaped rib roughness on the absorber plate. Int. J. Renew. Energy. 25(3), 341-369.

3. Han JC and Zhang YM (1992) High performance heat transfer ducts with parallel broken and V-shaped broken ribs. Int. J. Heat Mass Transfer. 35(2), 513-523.

4. Han JC, Gliksman LR and Rohsennow WM (1978) An investigation of heat transfer and friction for rib roughened surfaces. Int J. Heat Mass Transfer. 21(8), 1143-1156.

5. Karwa R (2003) Experimental studies of augmented heat transfer and friction in asymmetrically heated rectangular ducts with ribs on the heated wall in transverse, inclined, V-continuous and V-discrete pattern. Int. Comm. Heat Mass Transfer. 30(2), 241-250.

6. Karwa R, Solanki SC and Saini JS (1999) Heat transfer coefficient and friction factor correlations for the transitional flow regime in rib-roughened rectangular ducts. Int. J. Heat Mass Transfer. 42(9), 1597-1615.

7. Lau SC, McMillin RD and Han JC (1991) Turbulent heat transfer and friction in a square channel with discrete rib turbulators. ASME J. Turbomachinery. 113, 360-366.

8. Momin AME, Saini JS and Solanki SC (2002) Heat transfer and friction in solar air heater duct with $\mathrm{V}$-shaped rib roughness on absorber plate. Int. J. Heat Mass Transfer. 45(16), 3383-3396.

9. Muluwork KB, Solanki SC and Saini JS (2000) Proc. $4^{\text {th }}$ ISHMT-ASME heat and mass transfer Conf. and $15^{\text {th }}$ heat and mass transfer conf., Pune. India, pp: 391-398.

10.Prasad BN and Saini JS (1988) Effect of artificial roughness on heat transfer and friction factor in a solar air heater. Solar Energy. 41(6), 555-560.

11.Prasad K and Mullick SC (1983) Heat transfer characteristics of a solar air heater used for drying purposes. Appl. Energy. 13, 83-93.

12.Sadik K, Shah RK and Aung W (1987) Handbook of single phase convective heat transfer. Wiley, NY.

13.Taslim ME, Li T and Kercher DM (1996) Experimental heat transfer and friction in channels roughened with angled, V-shaped and discrete ribs on two opposite walls. J. Turbomachinery. $118,20-28$.
Lanjewar et al. Indian J.Sci.Technol. 